\title{
Event Study on Lifting Ban of Restricted Shares in Chinese Stock Markets
}

\author{
ZHANG Zhikun ${ }^{1, a}$ \\ ${ }^{1}$ Room 632, Building 10, Zisong Dormitory, Huazhong University of Sience and Technology, Wuhan, \\ Hubei, China \\ au201610005@hust.edu.cn
}

Keywords: Event Study; Restricted Shares; Chinese Stock Market.

\begin{abstract}
The long-term accumulation of the ban on the sale of restricted shares in China's stock market is extremely large and concentrated in the short-term. The pressure on the restrictions on the sale of restricted shares has long existed and has a huge impact on the market. By the method of event study, this paper conducts an empirical investigation from the existence of market reaction and the degree of market reaction. The results suggest that the pressure formed by the release of the restricted shares has accumulated a negative impact on the entire stock market and passed the restrictions on the stocks. The impact of shareholder and investor investment intentions impacts related stocks. At the same time, relevant suggestions were provided to reduce the impact of the lifting of the restricted shares.
\end{abstract}

\section{Introduction}

In 2019, there is a peak for lifting of the ban on China's restricted securities. In January only, 199 listed companies and a total of about 40.48 billion restricted shares ushered in lifting the ban. This Sudden increase in stock supply will have a certain impact on the whole market.

The restricted stock is literally a stock that is restricted to be traded. Before the split share reform in China, non-tradable shares of the listed companies (especially state-owned enterprises) accounted for a considerable portion of the whole volumes and enjoyed the same rights with tradable shares. Shares held by shareholders, issued to the public, and can be listed and traded on the stock exchange were known as tradable shares, while before the public offering the shares which were not listed for trading are known as non-tradable shares. Such situation where shares of the same listed company were divided into tradable shares and non-tradable shares is unique to the securities market in Mainland China. Through the share-trading reform, which was is to convert state-owned shares and legal person shares that could not be listed and traded into tradable shares, all the shares of the company were freely traded. However, in order to reduce the stock market turmoil caused by the large number of shares being listed, there is a limit to the time for this part of the shares going to publicly trade.

The restricted shares are classified into the original stocks in IPO hold by shareholders, the shares issued in a targeted manner, the stocks that are motivated by equity, the restricted shares of the share-trading reform, and the restricted shares of the shareholders' additional commitments, etc. Compared with events such as asset restructuring, transfer of control rights, and announcement of stocks' results, the release of restricted shares features the pre-opening of the banned information, the generality of the ban, the high income of the shareholders of the restricted shares, the huge scale of lifting the ban, and the lifting of the ban in short time and other special characteristics, so the impact of the restricted shares on the market is different from other events in terms of mechanis $m$ and consequences. If the amount of restricted shares was huge and the release cycle was short, it would bring large-scale stock supply, a major impact on the stock market. In many countries, there are problems in the stock market of restricted shares due to IPOs and refinancing. In the stock markets of developed economies from Europe to the United States, listed companies will also actively or passively restrict the issuance of shares during IPOs, for example, US IPO restricted shares generally account for approximately two-thirds of the total issued share capital of the IPO. The particularity of China is that the long-term accumulation of restricted shares is extremely large and concentrated in 
the short-term. In view of the long-term existence of the restrictions on the release of non-tradable shares in China and its potentially huge impact on the market, it is of great theoretical and practical significance for China to study this issue.

\section{Literature review}

Huang Jianhuan, Zhang Wei, and Yin Zhujia (2010) theoretically illustrated the micro-mechanism of the release of restricted stocks affecting the stocks and the stock prices with statistical analysis to collect evidence, and proved the market reaction of the restricted stocks being released. There were three major effects of the mechanism: cumulative effect, early reaction and reduction effect, and the most important reason for the fluctuation of China's stock market is the cumulative effect. The market reaction due to the early reaction and the reduction effect was significantly negative, which generally led to a negative market reaction. They believed that the important way to ease the pressure of lifting the ban on restricted shares is to substantially increase the market investment demand to effectively cope with the huge increase in the scale of stock supply.

Shu Wei, Han Yi (2008) used the event study to measure the reaction of the stock price of different companies in different situations where lifting rates and scales to the lifting of the ban varied. The research showed that, different from the general expectation, the lifting of the restricted shares had not decreased the stock earnings. The cumulative excess return rate when the market remained on a downswing was higher than when the market was rising. The big lifting ban was more stressful on the market than the small lifting ban. The cumulative excess return rate during the period of lifting the ban on large and medium-sized listed companies rose steadily, while the cumulative excess return rate of small-scale companies began to rise after the lifting of the ban.

Huang Jianhuan, Yin Zhujia, and Su Rui (2009) used a sequential game model and a static game model of simultaneous decision-making to analysis the micro-mechanism of the restricted stock market, and based on the event study for empirical analysis they studied the lifting of the ban on restricted shares in Chinese stock market, especially the reduction effect. The study found that the reduction effect might exist; when the relative size of the tradable shares and the banned shares were not much different, there was a self-stabilizing mechanism of the reduction effect. It is found that the self-stabilization mechanism of the reduction effect was often accompanied by a significant decline in the stock prices; after the release of the ban, a wait-and-see period existed, and the reduction effect was not significant during that period, but then there was a large-scale reduction behavior; the early response was obviously stronger than the reduction effect. The psychological impact of the lifting the ban on the restricted shares might be greater than the actual reduction of holding pressure. Therefore, it was believed that the focus of alleviating the restrictions on the lifting of the restricted shares and the pressure to reduce the holdings was to increase market investment demand and shareholding confidence.

Based on all China A-share data from Shanghai and Shenzhen stock exchange between 2006 to 2008 and through the event study to estimate the impact of the restricted shares on the market, Zhao Xiangqin, Xie Leike and Xin Yuan (2009) found that the financial characteristics of the company had little effect on the interpretation of CAR(cumulative abnormal returns). The stock market cycle had a strong interpretation effect on CAR, while the restricted stocks relatively stable.

Through the study of the price effect of lifting the ban on 1004 companies, Huang Zhangkai, Zhao Longkai, and $\mathrm{Zu}$ Guopeng (2010)found that the lifting of the ban would bring a significantly negative return, and the abnormal returns of non-government-controlled companies were significantly lower, that is, the this type of companies was more active in lifting shareholders' shares. For companies, which had both A-shares and $\mathrm{H}$-shares listed, the releasing of A-share would result in a decline in stock prices. The cross-sectional regression results showed that the abnormal income was positively correlated with the company's restricted state-owned shares, and was significantly negatively correlated with the arbitrage risk, and positively correlated with the abnormal turnover rate.

Wang Xiuli, Cai Rangfa (2011) comprehensively used of event study, single-sample T test and multiple linear regression methods and found that the lifting of the ban would have different effects on the market in different periods. Over the period with stock prices rising, the abnormal yield rate of 
the restricted shares was negative, and during the stock prices declining period, the abnormal yield of the restricted shares was positive. The more shares was released this time, the smaller the average cumulative abnormal rate of return; the fewer the number of shares released was, the greater the average cumulative abnormal rate of return; the higher the closing price of the stock was, the lower the average cumulative abnormal rate of return generated when the ban was lifted. The market impact caused by the lifting of the restricted shares was greater than the market impact of the initial release, additional issuance, and allotment of restricted shares. The former's abnormal rate of return was lower than the latter.

\section{Empirical Study on the Existence of Market Reaction}

\subsection{Basic assumption and data}

With the continuous lifting of the restricted shares, the relevant stocks often have a negative market reaction. The restrictions on the sale of restricted shares mainly impact the market from the supply and demand level, providing large-scale stock supply from the two sources to the market: first, the lifting of the restricted shares will increase the stock supply of the market itself, and the entire market will face a large-scale restricted stock. Under the pressure of lifting the ban, the stock price is bound to fall to bear the relevant pressure; at the same time, investors who lack shareholding confidence (mostly from the relevant companies, the banned shareholders) will choose to release the ban, and as more and more investors pay attention to the market impact of the lifting of the restricted shares, a large number of tradable shareholders who lost their shareholding confidence sold a lot, and a steady increase in the supply of related stocks in the market, severely curbed the market investment demand, resulting in imbalanced market supply and demand.

The impact of the lifting of the restricted shares on the market is not only reflected in the decline of related stocks, but also has a huge impact on the entire market. The lifting of the restricted shares of some stocks not only affects the stock price decline of the relevant stocks, but also leads to the decline of the relevant stock indexes in the positive feedback effect of the market. With the continuous lifting of the ban on restricted shares, the selling pressure from the relevant companies to lift the banned shareholders has also accumulated and increased. Under the cumulative pressure of the lifting of the ban on the sale of large-scale restricted shares, the stock price has fallen, and the willingness to sell stocks in the market has increased and investment demand gradually shrinking, the selling pressure from the relevant companies to lift the banned shareholders has also accumulated and increased, investors have chosen to reduce their holdings, resulting in imbalanced supply and demand in the market and gradually intensified, so that the stock price plummeted. On the occasion of constant accumulation of restrictions on the releasing of restricted stocks, the negative spiral forms and the balance of supply and demand in the market continues to deteriorate, causing the stock prices to plunge.

In order to test the existence of the market reaction mechanism for the lifting of the restricted shares and observe its characteristics, an empirical study is conducted below. For the stock market volatility of the entire market that may be caused by the ban on the restricted shares, this paper will use the Granger causality test to examine its existence.

This paper assumes that the lifting of the restricted shares is the cause of fluctuations in market yields. This paper uses the Granger causality test and data of Shanghai and Shenzhen 300 index yields to reflect the average one. The event study requires a lot of calculations, while in the Chinese stock market, more than 1,500 listed companies are involved in lifting the ban several times. It is not efficient to include all the banned incidents In terms of the market position and industry representation of the CSI 300 Index, this paper only selects the lifting of the index constituents. This article uses the daily data for the release of the restricted shares from January 2, 2018 to August 30, 2018. The data comes from Eastern Fortune. 


\subsection{Empirical results and analysis}

This paper selects the CSI 300 yield index, the number of new shares outstanding, the new circulation value, the cumulative number of new shares outstanding, and the cumulative number of new circulation market values, which respectively are represented by hs300rtn, Num, Va, acnum, Acva.

Table 1 Description of relevant indicators

\begin{tabular}{|l|l|}
\hline hs300rtn & CSI 300 yield index \\
\hline Num & the number of new shares outstanding \\
\hline $\mathrm{Va}$ & the new circulation market value, \\
\hline acnum & the cumulative number of new shares outstanding \\
\hline Acva & the cumulative number of new circulation market values \\
\hline
\end{tabular}

Table 2 Results of Granger causal test

\begin{tabular}{|c|c|c|c|c|}
\hline Original assumption & Obs & F-Statistic & Probability & Conclusion \\
\hline hs300rtn is not num's Granger cause & \multirow[t]{2}{*}{136} & 13.210 & 0.0000 & Reject \\
\hline num is not hs300rtn's Granger cause & & 0.570 & 0.4520 & Accept \\
\hline hs300rtn is not va's Granger cause & \multirow[t]{2}{*}{136} & 14.530 & 0.0000 & Reject \\
\hline va is not hs300rtn's Granger cause & & 0.031 & 0.8600 & Accept \\
\hline hs300rtn is not acnum's Granger cause & \multirow[t]{2}{*}{136} & 12.580 & 0.0000 & Reject \\
\hline acnum is not hs300rtn's Granger cause & & 0.695 & 0.4064 & Accept \\
\hline hs 300 rtn is not acva's Granger cause & \multirow[t]{2}{*}{136} & 14.830 & 0.2343 & Reject \\
\hline acva is not hs300rtn's Granger cause & & 0.061 & 0.8050 & Accept \\
\hline
\end{tabular}

The empirical results in Table 2 indicate that the number of new shares outstanding, the value of new circulation stocks, the number of accumulated new shares, and the market value of accumulated new shares are the Granger reasons for the yield of the CSI 300 index change. Otherwise, the market fluctuations have not lifted the restricted shares. Factors have significant effects on each indicator, and cumulative effects do not exist. It can be seen that the pressure formed by the lifting of the restricted shares during the observation period has accumulated a negative impact on the market yield, which proves that the cumulative effect exists and is one of the important reasons for the fluctuation of the Chinese stock market.

\section{Degree of Market Reaction}

This paper uses the event study to analyze the market reaction of lifting restricted shares. In the study, the date was taken as the event point, that is, the day of the lifting of the ban. The cumulative average abnormal return (CAR) of the sample stocks in a section before and after the lifting of the ban is an observational indicator of the market reaction of the restricted stocks. The window period is difficult to select. If it is too short, it is difficult to fully observe the market reaction. If it is too long, it may be interfered by other factors. Considering the short window period $[-10,10]$, the middle window period $[-30,30]$ and the long window period $[-90,30]$ and observe the situation of the lifting day.

\subsection{Theoretical analysis of market reaction}

From the micro level, the market reaction of the restricted shares is to express the impact of the stock price of the restricted shares on the release of the relevant information on the release of the restricted 
shares and the direct reaction of shareholders and investors. The mechanism can be divided into two aspects.

On the one hand, it is the impact of a large number of shareholder reductions. The essence of the lifting of the restricted shares is to increase the number of tradable shares circulating in the market, providing a large supply of the stock. Whether these new sources can become actual stock supply depends on the release of the lifting of the ban and the impact of stock price movements on the shareholders holding the restricted shares. When shareholders do not reduce their holdings within a certain period of time or within a certain stock price, they will not directly lead to an increase in stock supply, and the stock price will fall. However, in the case of a large scale of lifting the ban and a more dispersed shareholder, even if only a part of the shareholders reduce their shares, a large increase in the supply of stocks may have a huge impact on the stock price.

On the other hand, investors are selling stocks and investing in evasive behaviors caused by the lifting of the ban and the stocks reduction information. Other investors in the market are aware of the pressure on the restricted shares to lift the ban, especially after expecting a large scale of lifting the ban and a strong desire to lift the ban, which will inevitably respond, such as stopping the purchase and selling the shares of the relevant company in advance, or turning to invest in other markets, other company stocks, and will not easily invest in relevant stocks after the restricted shares are lifted, and may even continue to sell. These actions will increase the supply of related stocks and shrink the demand. When the supply and demand are unbalanced, the stock price will fall, or the trend will be weaker than the market average.

\subsection{Summary of CAR calculation methods}

Many researchers use market models to estimate abnormal returns and believe that stock returns are caused by factors from market and company. Given the stock return rate in t time $r_{t}$, we can get the equation:

$$
r_{t}=a+b r_{M t}+e_{t}
$$

where $r_{M t}$ is the market rate of return during that time period, $e_{t}$ is the result of security return caused by some company-level factors. The coefficient $b$ indicates the sensitivity to market returns and $a$ represents the average rate of return that the stock achieves when the market returns are zero. Therefore, in above formula, $r_{t}$ will be decomposed into two influencing factors at the market and company level. The company-level factor in this paper is the release of the restricted shares.

The residual term $e_{t}$ represents the portion of the return caused by the event, that is, the portion of the return that exceeds people's expectation of the stock returns based on changes in conventional market returns, provided that the stock is sensitive to the market, so that $r_{t}=a+b r_{M t}+e_{t}$ can be changed to $e_{t}=r_{t}-\left(a+b r_{M t}\right)$. This is an expression of the company's abnormal return over a given period of time.

The next step is to observe the window of the market effect. The day of releasing is $\mathrm{T}+0$. The previous transaction days are recorded as $\mathrm{T}-1, \mathrm{~T}-2, \ldots \mathrm{T}-\mathrm{A}$, and then $\mathrm{B}$ trading days are followed by $\mathrm{T}+1, \mathrm{~T}+2 \ldots \mathrm{T}+\mathrm{B}$, that is, the window period is from $\mathrm{T}-\mathrm{A}$ to $\mathrm{T}+\mathrm{B}$. There are $(\mathrm{A}+\mathrm{B}+1)$ trading days put together, and the appropriate short window of period and long window of period can be selected separately to observe the market reaction.

Calculate the abnormal rate of return of the sample stocks on different trading days of the corresponding observation window. In the study, the date of the lifting of the restricted shares was taken as the event point, that is, the day of the lifting of the ban. The cumulative average abnormal return (CAR) of the sample stocks in the interval before and after the lifting of the ban is an observation indicator for the market reaction of the restricted stocks.

$A R_{i, t}$, as the abnormal rate of return on the day $\mathrm{t}$ of the sample $\mathrm{i}$ is estimated based on the market adjustment model: $A R_{i, t}=r_{i, t}-r_{M, t} \cdot r_{i, t}$ and $r_{M, t}$ respectively, are the daily yield of the stock and the 
daily rate of return of the market, calculated using the closing price. The average abnormal rate of return for the $t^{t h}$ day in $\mathrm{n}$ samples is:

$$
A A R_{i, t}=\frac{1}{n} \sum_{i=1}^{n} A R_{i, t} .
$$

the cumulative average abnormal rate of return for the window period $[\mathrm{t} 1, \mathrm{t} 2]$ is:

$$
C A R_{t_{1}, t_{2}}=\sum_{t=t_{1}}^{t_{2}} A A R_{i, t} .
$$

\subsection{Empirical results and analysis}

Table 3 Granger empirical test results

\begin{tabular}{|c|c|c|c|}
\hline Observation interval & {$[-10,10]$} & {$[-10,30]$} & {$[-90,30]$} \\
\hline Number of samples & 2425 & 2425 & 2425 \\
\hline CAR $(\%)$ & -2.89 & -2.05 & 0.29 \\
\hline T value & -49.70 & -35.12 & 1.94 \\
\hline P value & 0.000 & 0.000 & 0.156 \\
\hline
\end{tabular}

The table 3 gives the results of the significant tests of CAR. The comprehensive analysis shows that the market reaction in the middle window period $[-10,30]$ and the short window period $[-10,10]$ is significantly negative (CAR is $-2.05 \%$ and $-2.89 \%$ ). Explain that the release of the restricted shares did have a negative impact on the sample stock price. The decline in stock price concentrated in the short-term release of the ban, indicating that the psychological impact of the restrictions on the sale of restricted shares made the majority of shareholders holding the restricted shares to implement large-scale reduction, the stock price fell, while investors in the market have been passively sold, transfer The investment intention has caused a serious impact on the relevant stock price. However, the long window period [-90,30] CAR is positive (CAR is $0,29 \%$ ), indicating that after the release of the restricted shares in advance, the impact of the ban on the stock price will be gradually advanced in the long window period. Digestion, the impact of the lifting of the ban on the market has been greatly reduced, and the reaction of the stock price has become more consistent with the overall trend of the market.

\section{Conclusions and enlightenment}

The impact of the lifting of the restricted shares on the market can be reflected in the macro mechanism, which can reflect the impact of the continuous accumulation of the restricted shares on the stock price of the whole market. From the microscopic point of view, the effect of the lifting of the restricted shares on the holding of shareholders and investors directly impact the stock price of the relevant stocks. This paper verifies the above viewpoint based on the empirical investigation of big data samples, and proves that the overall market reaction of the restricted shares is negative, the cumulative effect exists and is one of the important factors of market volatility, and also caused the relevant stocks to be in a certain period of time before and after the lifting of the ban. The stock price inside fell.

In view of the above problems, this paper finds that in order to cope with the cumulative effect of lifting the ban on restricted shares, the market must correspondingly increase the demand for stocks in the market to undertake a large supply of restricted stocks with increasing sources. By improving the information system of the stock market, the relevant information on the lifting of the restricted shares 
will be disclosed in advance, the panic of shareholders and investors will be reduced, and the stock price collapse of the stocks before and after the lifting of the ban will be avoided.

\section{References}

[1] Huang Jianhuan, Zhang Wei, Yin Zhujia. Market Reaction of Banned Sale Stocks: Mechanism and Characteristics Research[J]. The Theory and Practice of Finance and Economics, 2010, (1): $37-41$.

[2] Zhao Xiangqin, Xie Leike, Xin Yuan, Analysis of the Market Shock and the Influencing Factors of the Stock Market's Lifting of the Restricted Shares - Based on the Three-dimensional Perspective of the Lifting of the Ban, the Company's Characteristics and the Stock Market Cycle[J]. Contemporary Finance and Economics, 2009, (11): 57-62.

[3] Wang Xiuli, Cai Rangfa, Research on the Market Volatility and Influencing Factors of the Ban on the Sale of Restricted Shares__ A Study on the Event of Lifting the Ban on A-share Restricted Shares[J]. Journal of Shanxi Finance and Economics University. 2011, (1): 49-57.

[4] Li Qingfeng, Huang Weijia, Research on the Market Effect and Influencing Factors of the Restriction of Restricted Shares__ Based on the Event Research Method and the Shanghai and Shenzhen 300 Index Samples[J]. Macroeconomic, 2011, (7): 56-63.

[5] Huang Jianhuan, Yin Zhujia, Su Rui, Research on the Effect of Reducing the Shareholding of the Restricted Stocks in China's Stock Market. Journal of Management Science[J]. 2009, (4): 97-106.

[6] Huang Zhangkai, Zhao Longkai, Zu Guopeng, Research on the Price Effect of Lifting the Ban on Restricted Shares[J]. Journal of Financial Research, 2010, (9): 123-143.

[7] Shu Wei, Han Yi, Market Reaction of Restricted Sale of Stocks[J]. Exploration of Financial Theory, 2008, (4): 59-62. 